\title{
Polyorganosilazane Preceramic Binder Development for Reaction Bonded Silicon Nitride Composites
}

\author{
David L. Mohr and Thomas L. Starr \\ Materials Science and Technology Laboratory \\ Georgia Tech Research Institute \\ Atlanta, Georgia 30332 \\ November, 1992 \\ Research Sponsored by the U. S. Department of Energy, \\ Fossil Energy \\ Advanced Research and Technology Developmeni Materials Program \\ Report Prepared by \\ GEORGIA TECH RESEARCH INSTITUTE \\ Georgia Institute of Technology \\ Atlanta, Georgia 30332 \\ under \\ Sub-contract 19X-00184C \\ for \\ OAK RIDGE NATIONAL LABORATORY \\ Oak Ridge, Tennessee 37831 \\ managed by \\ MARTIN MARIETTA ENERGY SYSTEMS, INC. \\ for the \\ U. S. Department of Energy \\ under Contract No. DE-AC05-840R21400
}




\section{TABLE OF CONTENTS}

Table of Contents $\ldots \ldots \ldots \ldots \ldots \ldots \ldots \ldots \ldots \ldots \ldots \ldots$ ii

Table of Figures $\ldots \ldots \ldots \ldots \ldots \ldots \ldots \ldots \ldots \ldots \ldots \ldots \ldots$ iii

INTRODUCTION $\ldots \ldots \ldots \ldots \ldots \ldots \ldots \ldots \ldots \ldots \ldots \ldots \ldots \ldots \ldots$

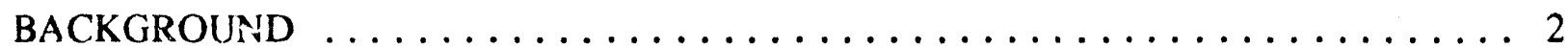

EXPERIMENTAL DETAILS $\ldots \ldots \ldots \ldots \ldots \ldots \ldots \ldots \ldots \ldots \ldots$

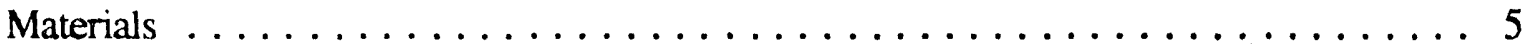

Ceramic Fabrication - Monolithic and Whisker Reinforced $\ldots \ldots \ldots \ldots \ldots$

Fiber Reinforced Composite Fabrication $\ldots \ldots \ldots \ldots \ldots \ldots \ldots \ldots \ldots$

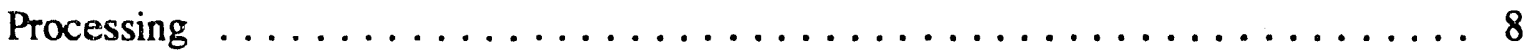

RESULTS AND DISCUSSION $\ldots \ldots \ldots \ldots \ldots \ldots \ldots \ldots \ldots \ldots \ldots \ldots \ldots$

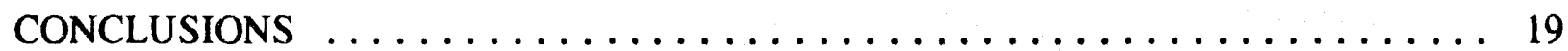

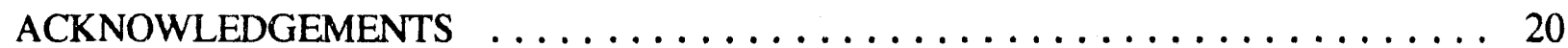

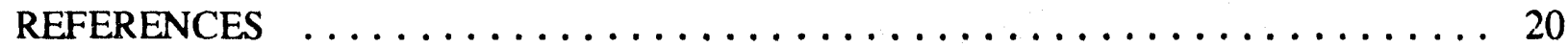




\section{TABLE OF FIGURES}

Figure

1. Structure of Polysilazane Ceramic Precursors. $\ldots \ldots \ldots \ldots \ldots \ldots \ldots$

2. Composite processing: Nicalon cloth laminates. . . . . . . . . . . . 9

3. Extent of reaction of silicon based on nitrogen consumption $(\bullet=$ attritor milled silicon, $\mathrm{x}=$ attritor milled silicon with $40 \mathrm{v} \%$ OMSZ binder $) \ldots \ldots \ldots \ldots \ldots \ldots \ldots$

4. X-ray diffraction data for RBSN control sample. $\ldots \ldots \ldots \ldots \ldots \ldots \ldots \ldots$

5. X-ray diffraction data for RBSN with 40 vol\% OMSZ binder. $\ldots \ldots \ldots \ldots \ldots$

6. Density of RBSN samples versus initial OMSZ binder content. $\ldots \ldots \ldots \ldots \ldots$

7. Mercury porosimetry data for nitrided samples: SN87 (RBSN control) and SN86

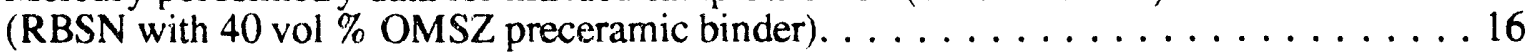

8. Mercury porosimetry data for RBSN sample initially containing 50 vol\% OMSZ . . . 16

9. Electron micrograph of fracture surface of fabric reinforced RBSN composite. . . . . 18

10. Electron micrograph of fracture surface of fabric reinforced RBSN composite

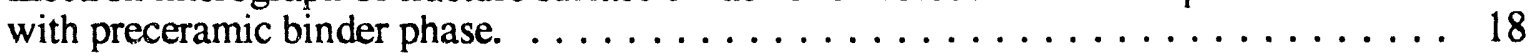




\section{INTRODUCTION}

Many potential applications exist for high temperature materials. Ceramic composites with improved fracture toughness compared to traditional ceramics continue to hold great promise for increasing the efficiency of fossil fuel utilization. Fabricability is an important factor in such applications, especially for the relatively large and complex shapes used for fossil energy conversion systems. However, with traditional ceramic fabrication techniques, it is difficult to process a ceramic composite matrix to near full density without degrading the fiber phase. Alternative routes to the formation of ceramic materials, such as reaction bonding or pyrolytic conversion of polymers to ceramic materials, promise improvements in the processibility of ceramic composites.

Reaction bonding is a near-net-shape fabrication method for the formation of reaction bonded silicon nitride (RBSN). In the conventional process, this requires reaction of nitrogen with relatively coarse silicon powder at temperatures which would degrade the available fibrous reinforcements. Recently developed processes using submicron silicon powder reduce this problem by decreasing the maximum nitriding temperature and time required to form silicon nitride $[1,2]$. However, it is difficult to produce parts with high green densities using these submicron powders. Fine powders with relatively narrow size distributions do not pack efficiently. Low packing density leads to more total porosity in the green body and thus in the nitrided material.

Ceramic processes typically employ fugitive binders in order to maintain dimensional integrity during processing. The alternative use of polysilazanes as binders in ceramic composites could improve processibility and reduce porosity in these systems, as well as change the macroscopic and microscopic morphology and crystallinity of the resultant product [3]. The objective of this research is to examine the use of preceramic binders in a reaction bonded silicon nitride system.

Reseach sponsered by the U. S. Depertment of Energy, Fossil Energy AR\&TD Materials Program, DOE/FE AA 151010 0, Work Breakdown Structure Element GT-1. 


\section{BACKGROUND}

There are many general reviews of the development of ceramic composites. A significant effort has been expended on developing ceramic matrices which can be densified without imposing processing conditions which degrade the fiber phase. Some of the processing routes to form such matrices include reaction bonding, which has been briefly discussed above, and chemical vapor infiltration $[4]$. The relatively new polymer pyrolysis route to ceramics has been found to be unsuitable for matrix formation without the addition of other phases as fillers.

Chantrell and Popper $[5]$ conceived of the conversion of tractable polymers having inorganic backbones to inorganic materials over twenty-five years ago. The yield. shape and microstructure of a polymer pyrolysis-derived product depends on the precursor materials used and the processing conditions. Polyorganosilazanes are viable polymeric precursors to $\mathrm{Si}-\mathrm{C}-\mathrm{N}$ or $\mathrm{Si}-\mathrm{N}$-C-O ceramic materials [6]. When these materials are heated to $800^{\circ} \mathrm{C}$ in an inert atmosphere, a glassy ceramic product is obtained which contains primarily silicon, nitrogen and carbon. A patent entitled "Production of Shaped Articles of Silicon Carbide and Silicon Nitride" was issued to Winter and Verbeek [7]. The material discussed is a silazane made by reacting a halogenosilane with ammonia. Silazanes of many different compositions were examined or proposed, with the goal of obtaining the appropriate degree of crosslinking to allow good ceramic yield while maintaining processibility. This patent lists many possible shaped objects which could be made from this material, including fibers, flakes, powders, films, and foams. Particularly relevant to this study is the description in the patent of the use of the silazane essencially as a matrix for ceramic powder, or as a preceramic binder. It describes the possibility of forming mixtures of silicon carbide or silicon nitride powder with the silazanes. The mixture would be pressed into shaped articles, preferably under vacuum, at temperatures at which crosslinking occurs, eliminating volatiles. The molded article would then be heated to between $800^{\circ}$ and $2000^{\circ} \mathrm{C}$. The possibility of using silazanes as the matrix for a fibrous structure is also briefly mentioned. 
Several other investigators have made mention of the concept of using a precursor material as a binder in a traditional powder process $[8,9,10 \mid$. A research group at Ethyl Corporation \|\| has examined polysilazanes in several applications. For example, they investigated samples which had been dry-pressed from mixtures of 20-30 w\% polysilazane material together with silicon carbide or silic on nitride powders. Thermal pretreatment and pyrolysis of the samples could be carried out at temiperatures which are well below temperatures normally required to sinter such powders alone. The samples produced in such manner exhibited a microstructure consisting of submicron ceramic powder particles in an amorphous nanoporous polymer derived matrix. The relationship between the sample microstructure and physical properties was discussed. The densiiy of the "composite" samples is relatively low $(2.3 \mathrm{~g} / \mathrm{cc})$ compared to fully dense silicon carbide $(3.2 \mathrm{~g} / \mathrm{cc})$, implying pore content of greater than 22 vol \%. However, the strength, which went through a maximum of about $415 \mathrm{MPa}$ at binder contents of between 20 and $30 \mathrm{vol} \%$, is comparable to that for high quality, dense sintered silicon carbide materials. This high specific strength was thought to be due to the small, uniform size of the pores, which range from 0.1 to $4.5 \mathrm{~nm}$.

A preceramic polymer has been used use to increase the density of reaction bonded silicon nitride by infiltration into the ceramic after nitriding [12]. The fine microstructure of the RBSN was observed to impair penetration of the preceramic polymer into the interior of the sample. Pyrolysis of the sample resulted in the surface densification of the RBSN.

Thus, several applications for polysilazane ceramic precursors have been described in the literature, including the formation of fibers, coatings and binders. However, the use of polysilazane binders to aid in forming and densification of an RBSN system has not been explored in the literature. In the work described herein, pore volume in a green silicon powder compact (which often approaches $40 \%$ of the total volume) was filled with a polymeric phase which was subsequently converted to a ceramic material. The net porosity of the material was reduced. Subsequent nitriding of the silicon powder then further densified the material. This system holds promise for the production of ceramic matrix material which can be densified using moderate 
processing conditions, as well as possible improvements in dimensional stability during processing.

The fabrication and thermochemical conversion of this material into a dense ceramic is a multi-step process. First, the green body must be formed containing submicron silicon powder, preceramic binder, and fiber (in the case of a composite). Then, a "pretreatment" step usually is performed to crosslink the preceramic polymer, usually heating the material with the possible addition of co-reactants. At this point, the matrix material would consist of silicon powder in a crosslinked polymer phase. This material would then be pyrolyzed in an inert atmosphere (to 900$)^{\circ}$ C), converting the polymer phase to an amorphous ceramic phase. The material is then heated in nitrogen $\left(1200^{\circ} \mathrm{C}\right)$ to convert the silicon metal to silicon nitride. This process is not significantly more complex or time consuming that the nitriding of a silicon powder compact which contains a fugitive binder.

Some inferences can be made concerning the use of preceramic binders in RBSN composites. One of the primary problems in making good ceramic matrix composites lies in degradation of fiber properties during processing. Currently available fibers (usually derived from polymeric ceramic precursors) lose much of their strength when exposed to high temperatures; this effect is aggravated above $1200^{\circ} \mathrm{C}$. Because the RBSN-preceramic binder matrix system can be densified at or below $1200^{\circ} \mathrm{C}$ at reiatively short time, there is great promise that a ceramic composite can be fabricated using this system with reduced degradation compared with conventional processes.

Another possible benefit resulting from the use of preceramic binders in ceramic composite is added dimensional stability during processing. Currently the ceramic composites processed via reaction bonding must be constrained from increasing in volume during reaction bonding. Because the polysilazanes are crosslinked at temperatures of less than $300^{\circ} \mathrm{C}$, these composites could be molded and then crosslinked in a metal mold. This crosslinked structure may be sufficient to maintain dimensional stability through subsequent processing, hopefully removing the need to constrain the part in a refractory fixture during nitriding. 
The preceramic binders system may have as an added benefit reduced permeability to gas transport. This may reduce degradation of the fibers under use conditions.

The goal of this research is to evaluate polysilazane binders in monolithic and composite silicon nitride ceramic systems as developed above, especially examining the affect of addition of the polysilazane binder on the density and morphology of the composite, which in turn can influence the strength and composite behavior of the material. Initial results have been published elsewhere $[13,14]$. Future research will investigate the effects of the addition of preceramic binders on the performance properties (strength, toughness, creep resistance) of reaction bonded materials.

A study of the chemical changes which occur during pretreatment and pyrolysis of polyorganosilazanes has also been performed in conjunction with this research. These data will be published separately. Preliminary results have been published elsewhere $[15,16]$.

\section{EXPERIMENTAL DETAILS}

\section{Materials}

Two types of polysilazane materials were examined:

(i) A oligomethylsilazane (OMSZ) (a (1,2-dimethylsilazane)(1-methylsilazane) copolymer) (PS116, Petrarch Corporation)

(ii) A polymethylsilazane (PMSZ) obtained from the Nichimen Corporation (NCP-200, manufactured by the Chisso Corporation, Japan).

The PMSZ material was a copolymer of higher molecular weight than the Petrarch copolymer OMSZ, with a number average molecular weight of 1000-1500 daltons (which implies an approximate degree of polymerization of 16-25). The proposed structures are shown in Figure 1. The OMSZ material was claimed to allow char yield of $50-55 \%$ by Petrarch literature. 


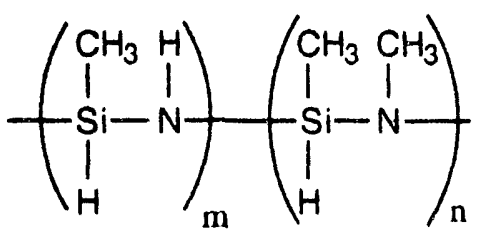

OMSZ

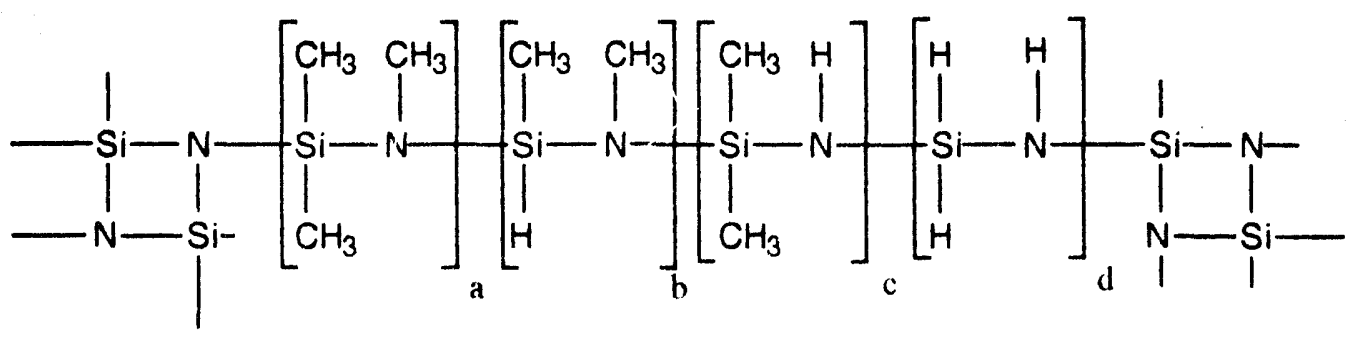

PMSZ

Figure 1. Structure of Polysilazane Ceramic Precursors. 
Silicon metal powder was obtained from Keminord Industries (distributed by Superior Graphite Company). The manufacturer lists a median particle size of $7 \mathrm{~mm}$ diameter. The particle size was reduced using an attritor milling machine (model 01-HD) made by the Union Process Company with steel vessel and grinding media. The powder was milled for 24 hours in toluene. Nitrogen adsorption (BET) analysis indicated a surface area for this, fine powder of about $18 \mathrm{~m} 2 / \mathrm{g}$, corresponding to a weight average diameter of about $0.5 \mu \mathrm{m}$, vased on Sedigraph measurements on similar samples which had the same BET surface area.

Fibrous reinforcement consisted of either $\mathrm{SiC}$ whiskers, obtained from the American Matrix Company, or Si-C-O Fibers (Nicalon, Ceramic Grade), obtained from Dow Corning.

\section{Ceramic Fabrication - Monolithic and Whisker Reinforced}

Monolithic ceramic samples were prepared by filter pressing. This technique involves preparation of a thick viscous mixture of the components (submicron attritor milled silicon powder. polysilazane, and toluene which had been stored over a molecular sieve to remove water), which is then pressed between microporous filters using a hydraulic press to remove excess solvent. Samples were pressed in a matched die mold to approximately $34.5 \mathrm{MPa}$ (5000 psi). Composite and monolithic samples were prepared in parallel. Whisker reinforced composites were produced in like manner, with care taken to insure that the whiskers were well dispersed to avoid clumping.

\section{Fiber Reinforced Composite Fabrication}

The preparation of fabric reinforced composites was more involved than monolithic or short fiber composites. Samples were made either as two inch diameter laminated disks or as two inch by one inch rectangular laminates. Initially, fabric layers were cut in the appropriate size, washed with acetone to remove sizing, dried, and weighed. They were then dipped into a dispersion composed of silicon powder in ethanol ( $35 \mathrm{v} \%$ silicon in ethanol). The layers were weighed, and the percentage of powder to fiber was calculated. The desired value for the ratio of powder taken 
up onto the fiber to the weight of fiber was seventy percent, which should result in samples with 40 vol $\%$ silicon nitride, 40 vol $\%$ fiber, and 20 vol\% porosity when fully processed.

The procescing of fabric reinforced composite control samples was performed as follows (Figure 2). The major steps were wetting, pressing, clamping, removal of wetting agent, and finally, nitriding. Each layer was dipped in glycerin, which significantly improved green density after pressing, due to increased lubrication and mobility of the powder during pressing. Then the layers were stacked in 0/90 degree orientation until the desired sample thickness was obtained (seven layers for these samples). The stack of layers was placed between two flat stainless steel plates with alignment posts. The assembly was then placed in a hydraulic press, and pressed to moderate pressures (about 3.3 $\mathrm{MPa}$ ). This removed excess glycerin while allowing the silicon powder to redistribute to increase green density. Composite samples with precursor binder were prepared in a similar manner, substituting known amounts of preceramic binder for the glycerin.

The laminate was removed and placed in a refractory fixture. This consisted of two round silicon nitride plates and two inner liners which have many holes to allow gaseous species to pass during processing. Tungsten alignment rods passed through the assembly. Pressure was maintained on the sample during processing by placing several shims onto these locating rods, holding them together with tungsten locking pins. This fixture allowed the sample to be held and restrained from "springing back" to a greater thickness during processing. Thickness restraint during processing is needed to obtaining adequate density in the resultant composite part [17].

\section{Processing}

In general, densification of the RBSN - preceramic binder system was carried out in three steps first, a pretreatment step which changes the chemical structure of the polymer to reduce subsequent volatilization, then a pyrolysis step (up to $800-1200^{\circ} \mathrm{C}$ in an inert atmosphere) in which the polymer was converted to an amorphous ceramic, and then a nitriding step whereby silicon is converted to silicon nitride. 


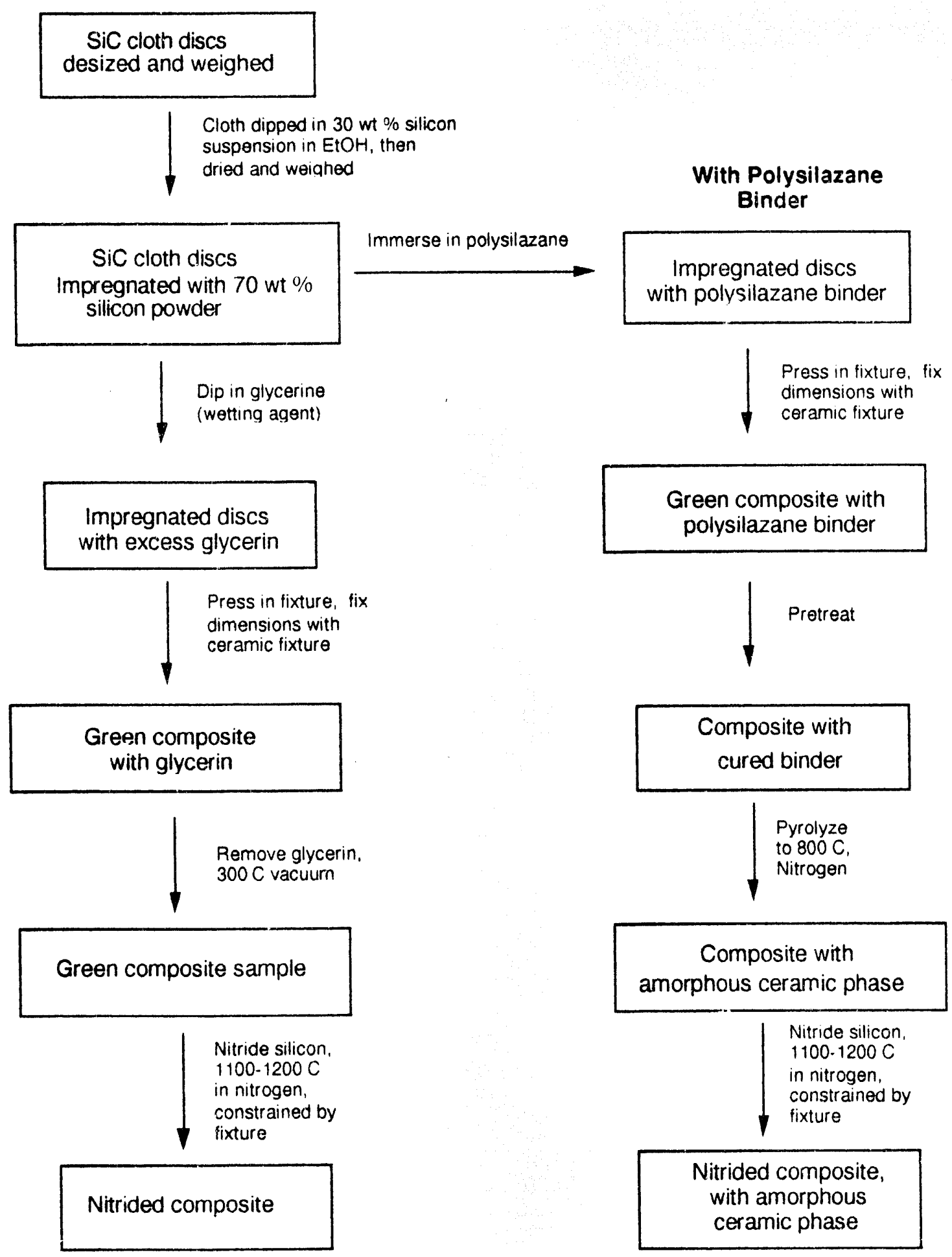

Figure 2. Composite processing: Nicalon cloth laminates. 
The composite laminate samples which contained the preceramic binder were held under pretreatment conditions (moist air at $200^{\circ} \mathrm{C}$ for 6 hours) constrained by the refractory fixture. Monolithic and whisker reinforced sarnples were exposed to similar conditions unrestrained. Fabric reinforced composite control samples which contained the wetting agent were placed in a vacuum furnace and heated to approximately $200^{\circ} \mathrm{C}$ under vacuum for several hours to remove the wetting agent.

The polysilazanes are typically pyrolyzed at temperatures of about $800^{\circ} \mathrm{C}$ in nitrogen. The temperature was rarıped to maximum temperature at $2^{\circ} \mathrm{C} /$ min. Monolithic samples were pyrolyzed in a tube furnace, while composite samples were pyrolyzed (constrained) in the nitriding furnace described below.

The reaction bonding experiments were performed in a computer controlled nitriding system which has been described earlier [18]. The main component of the system was a low mass, water cooled furnace using tungsten elements and having a maximum temperature capability of $2200^{\circ} \mathrm{C}$ in vacuum. system was controlled by a CamileTM 2000 (Dow Chemical) data acquisition and control sysi , which was interfaced to an IBM-AT compatible microcomputer which provides the user interface and data storage facilities. The system monitors nitriding parameters (pressure, moles of $\mathrm{N}_{2}$ gas used, temperature) on a real-time basis and adjusts conditions (primarily temperature and gas flow) to control nitriding rate.

Typically, nitriding a sample containing the ultra-fine attritor milled silicon powder was performed utilizing the following procedure. A sample was inserted into the nitriding furnace and the furnace was evacuated until the pressure dropped and remained below $10^{-5}$ torr. The temperature was then ramped to $900^{\circ} \mathrm{C}$. A mixture of $95 \%$ nitrogen $/ 5 \%$ hydrogen gas was then allowed to flow into the furnace. The furnace was heated $\left(20^{\circ} \mathrm{C} / \mathrm{min}\right)$ to $1100^{\circ} \mathrm{C}$, at which point the nitriding reaction begins to occur. The temperature was then ramped to $1200^{\circ} \mathrm{C}$ at $0.5^{\circ} \mathrm{C}$ per minute, and the pressure was automatically maintained to within approximately 5 torr of ambient pressure by adding nitrogen as it was consumed by the reaction. The moles of nitrogen added to 
the system were monitored using a mass flow meter, while the moles of gas present in the furnace was calculated by monitoring the temperature and pressure in the system.

Fully processed sample density was determined via a water displacement method (following ASTM C. 373-56). A mercury intrusion orosimeter was utilized to characterize pores in the 3.6 $\mathrm{nm}$ to $210 \mu \mathrm{m}$ size range. The instrument used to detect pore sizes in the range $(30-210 \mu \mathrm{m})$ was a Quantachrome Autoscan Filling Apparatus. Smaller pore sizes were detected using a higher pressure mercury porosimeter (Quantachrome Autoscan-331 Porosimeter) which imposed higher pressures corresponding to pores as small as $3.6 \mathrm{~nm}$. Sample morphology was evaluated using optical and electron microscopy (SEM \& TEM). Crystalline composition of the ceramic samples was determined using a Rigaku Geigerflex X-ray diffractometer.

\section{RESULTS AND DISCUSSION}

Monolithic, whisker reinforced, and cloth reinforced reaction bonded silicon nitride samples have been produced. Modification of the nitriding process due to addition of a polysilazane binder has been examined. The density, porosity, morphology, and other characteristics of ceramic samples have been evaluated. Some of the results are discussed below.

Some alteration to the nitriding reaction kinetics of these samples was noted due to the addition of the polysilazane binder. The nitriding reaction (as monitored by nitrogen consumption) was slowed sightly by the addition of the preceramic binder, though the reaction eventually reached the same conversion as observed in control samples after a short hold at maximum temperature (Figure 3). The slower rate of the nitriding teation may have been due to the higher green density of samples containing the preceramic binder which may have limited transport of nitrogen into the powder compact or to other factors. The reaction of nitrogen with silicon powder can follow several mechanistic pathways, which influence both the kinetics of the reaction and the type of products which are produced. These products were characterized via x-ray diffraction analysis. 


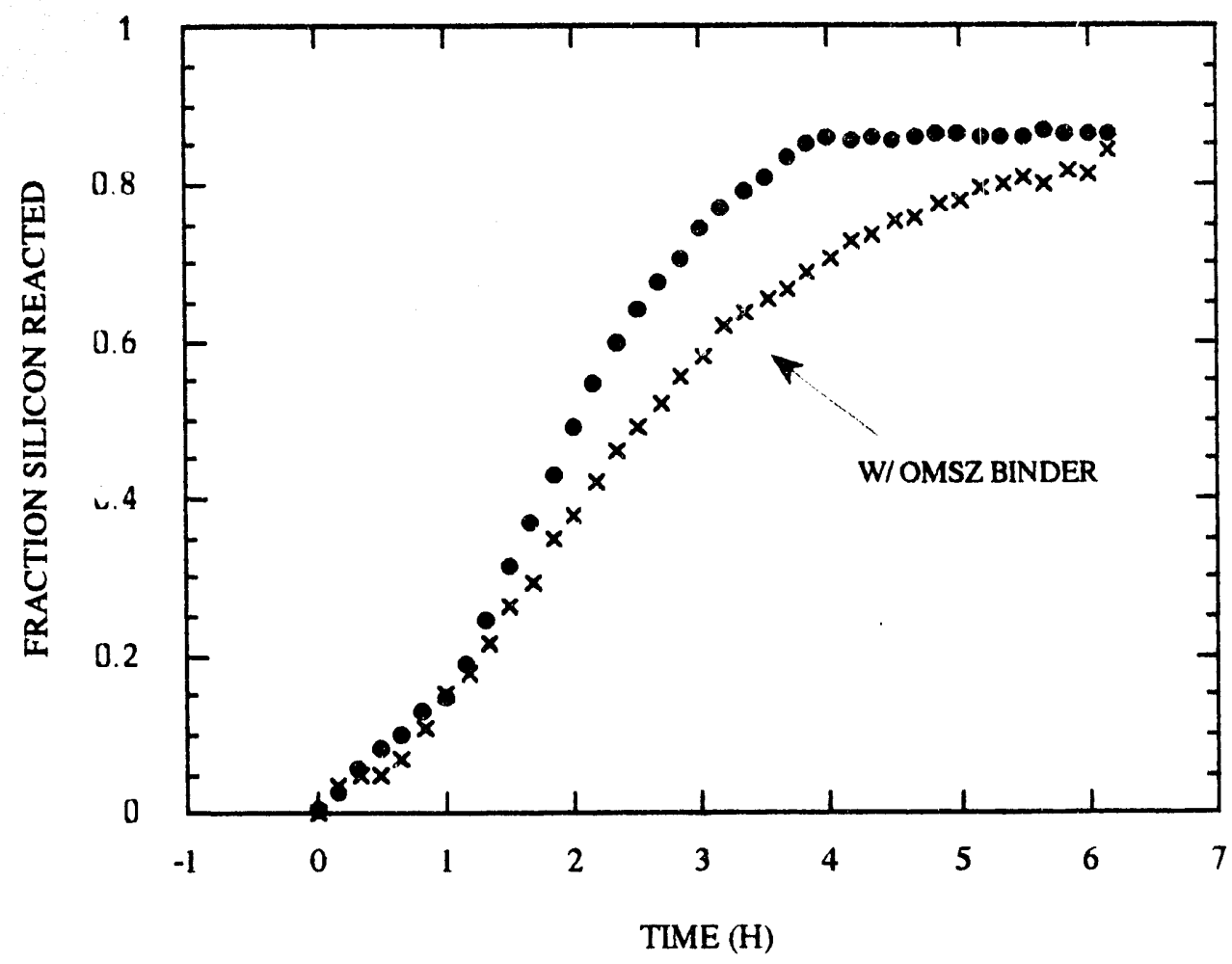

Figure 3. Extent of reaction of silicon based on nitrogen consumption $(\bullet=$ attritor milled silicon, $x=$ attritor milled silicon with $40 \mathrm{v} \%$ OMSZ binder). 
$\mathrm{X}$-ray diffraction data revealed that samples which contained the OMSZ binder had higher content of $\alpha$-versus $\beta$-silicon nitride than the control samples (Figures 4 and 5). Alpha silicon nitride is formed by vapor-phase reactions, while beta silicon nitride is thought to be formed via VLS reactions and to a smaller extent via reaction of $N_{2}$ with the silicon surface $|19|$. The reactions which occur and the products which are formed during nitriding are fundamentally influenced by the composition of the silicon powder, the reaction temperature, and the atmospheric composition. The primary chemical species which is evolved from polysilazanes in the nitriding reaction's temperature range is hydrogen [15]. Generally, the addition of hydrogen to the atmosphere during nitriding promotes the nitridation of $\mathrm{SiO}$ vapor $|19|$. Active oxidation of the silicon surface and nitridation of the $\mathrm{SiO}$ generated would lead to increased $\alpha-\mathrm{Si}_{3} \mathrm{~N}_{4}$ content | $19 \mid$ such as that observed in samples containing a polysilazane binder.

The density of monolithic and whisker reinforced samples which contained preceramic binders was significantly increased compared to that of control samples. Density data for monolithic samples initially containing various binder contents is shown in Figure 6. Density increased from about $2.0 \mathrm{~g} / \mathrm{cm}^{3}$ to $2.4 \mathrm{~g} / \mathrm{cm}^{3}$ as the initial volume fraction of polysilazane increased from $0 \%$ to $50 \% . \mathrm{SiC}$ whisker reinforced composites were produced which exhibited the same increase in density as shown for the monolithic samples. For example, the density of composite samples containing 5 vol. \% SiC whiskers increased from $2.01 \mathrm{~g} / \mathrm{cm}^{3}$ to $2.46 \mathrm{~g} / \mathrm{cm}^{3}$ with the addition of 40 vol. \% OMSZ preceramic binder. The increase in density in samples which contained the polysilazane binder means that the total volume fraction of porosity in these samples was significantly reduced.

The pore size distribution of these samples was correspondingly modified. Mercury porosimetry showed that the average open pore size as detected by that method was decreased from approximately $0.05 \mu \mathrm{m}$ to $0.01 \mu \mathrm{m}$ due to incorporation of the OMSZ binder (Figure 7). The evolution of the pore sizes through the process was also particularly interesting. Figure 8 shows 


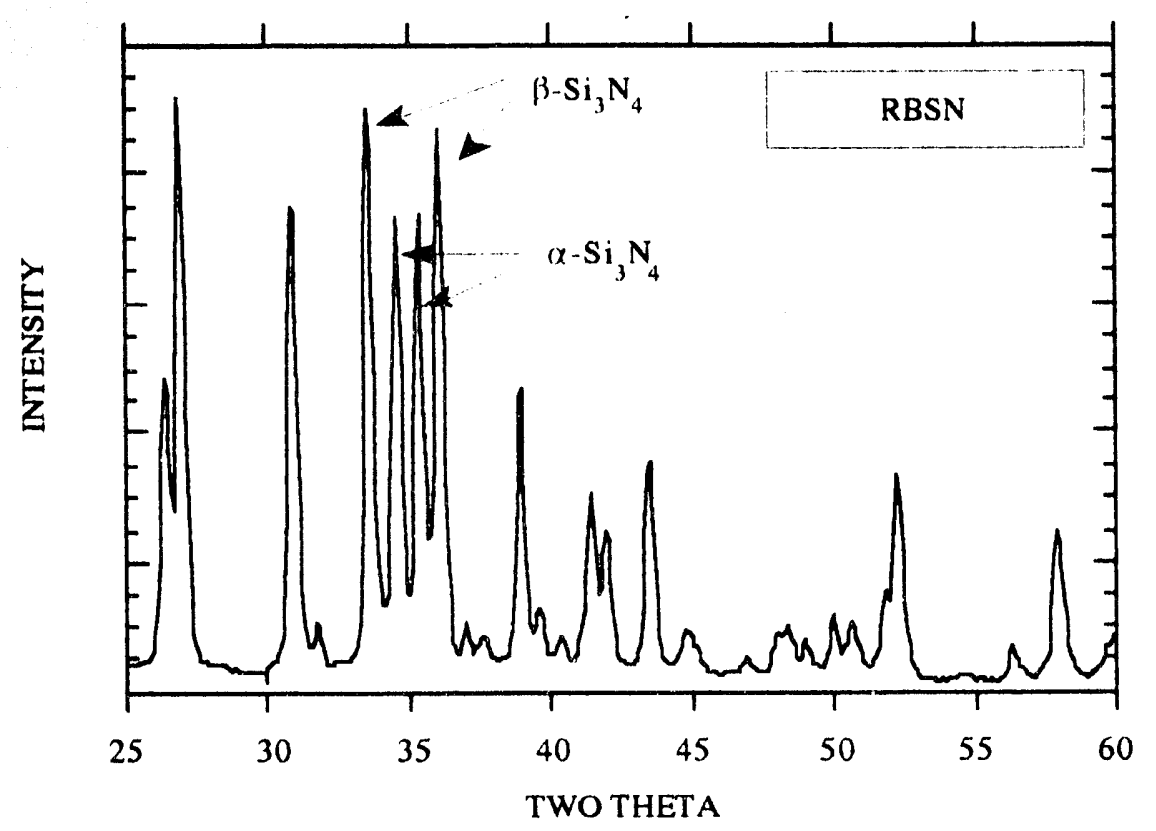

Figure 4. X-ray diffraction data for RBSN control sample.

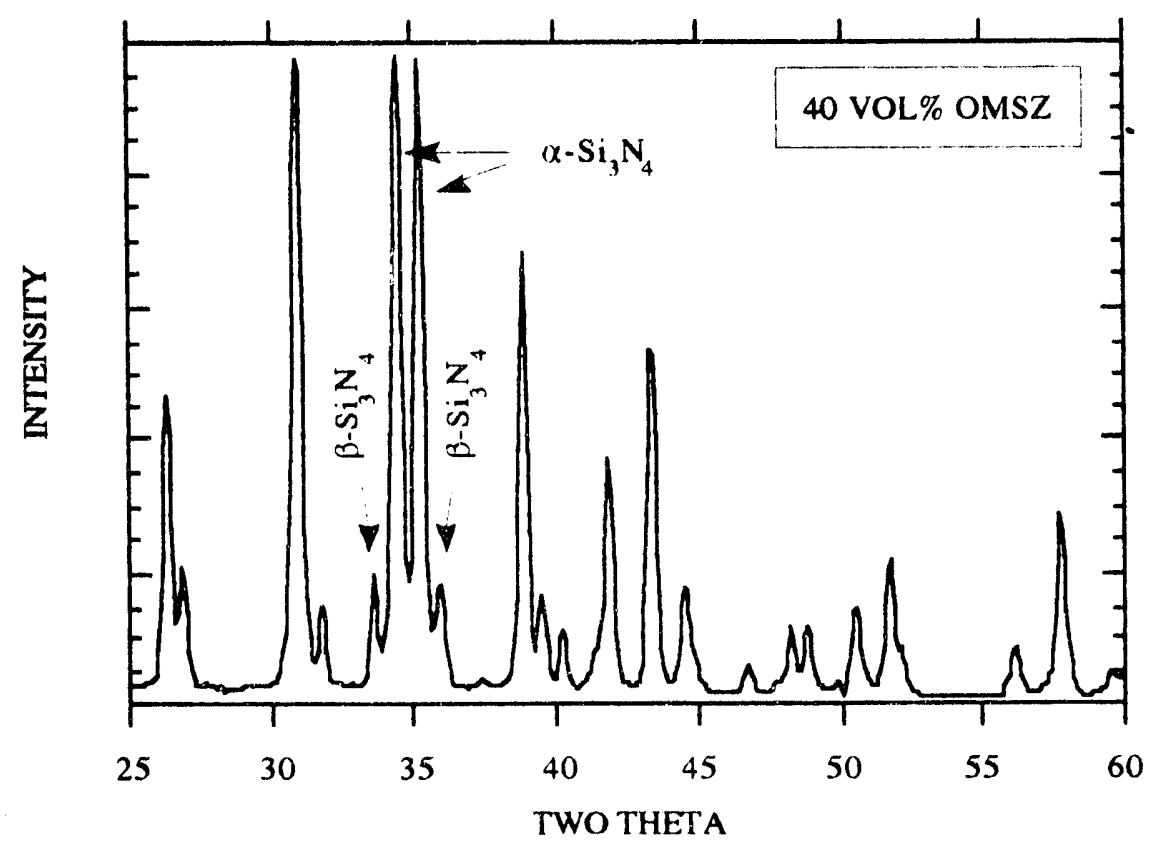

Figure 5. X-ray diffraction data for RBSN with $40 \mathrm{vol} \%$ OMSZ binder. 


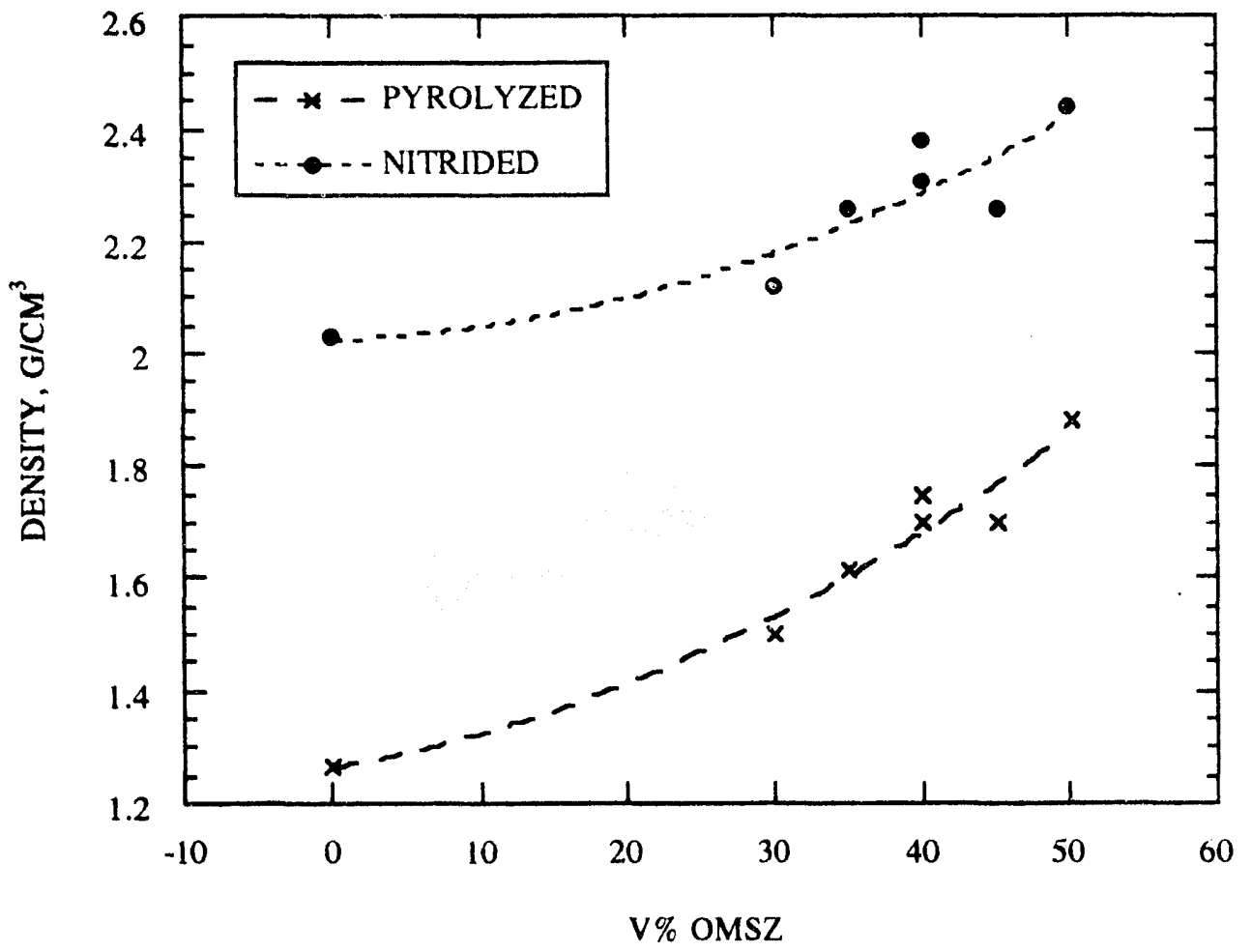

Figure 6. Density of RBSN samples versus initial OMSZ binder content. 


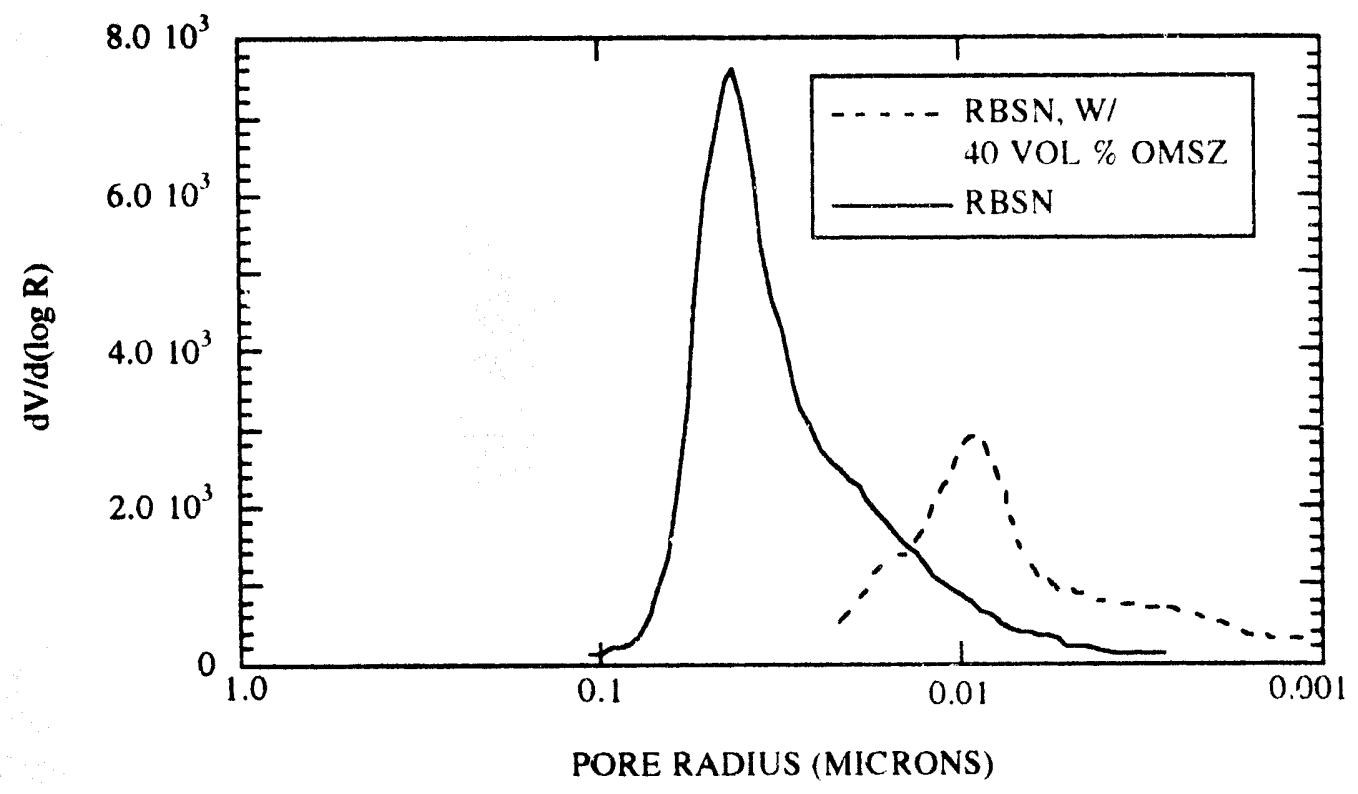

Figure 7. Mercury porosimetry data for nitrided samples: SN87 (RBSN control) and SN86 (RBSN with 40 vol \% OMSZ preceramic binder).

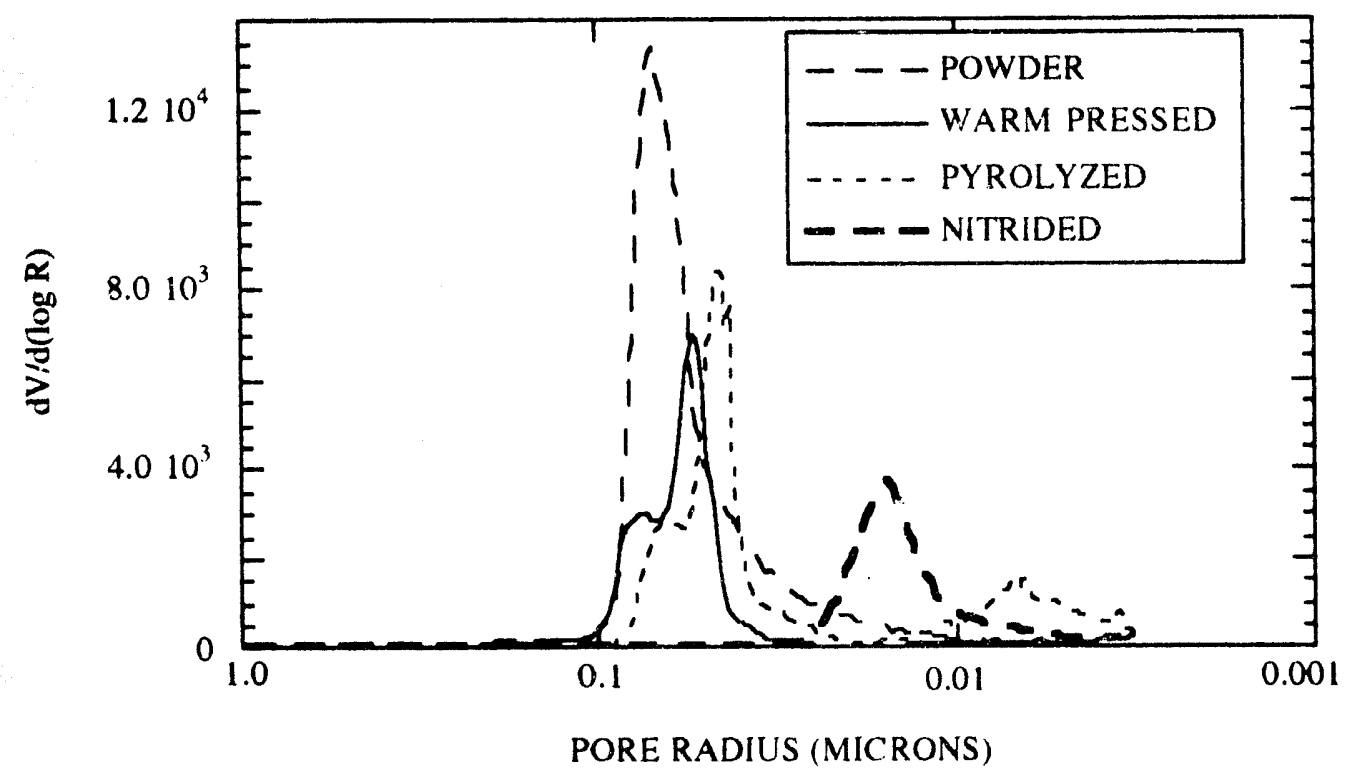

Figure 8. Mercury porosimetry data for RBSN sample initially containing 50 vol\% OMSZ. 
mercury porosimetry data for materials which were processed to different extents - an unfilled attritor milled silicon powder compact, and a similar sample which initially contained $50 \mathrm{vol} \%$ OMSZ after pretreatment ("warm pressed"), pyrolysis, and nitriding. Many of the larger pores were apparently filled by the polysilazane binder in that sample ("warm pressed") compared to the powder compact. Subsequent pyrolysis caused the formation of a new population of small pores. The product of the nitriding reaction apparently filled the larger pores, reducing the average pore size to approximately $0.01 \mu \mathrm{m}$.

The morphology of samples which contained the polysilazane binders was observed using optical and electron microscopy. The samples exhibited uniform morphology, with no cracking due to dimensional changes of the polysilazanes during pyrolysis.

Thus the addition of a preceramic binder to the reaction bonded silicon nitride system results in increased density, decreased total porosity and reduced pore sizes. The affect that these changes in microstructure have on mechanical properties (strength, tougnness, creep resistance, etc.) of these materials remains to be investigated.

Foregoing attempts to produce continuous fiber (fabric) reinforced composites via this method have not realized improvements in density and porosity corresponding to those which have been observed for monolithic and whisker reinforced samples. The lack of improvement in density is thought to be due to incomple ie development of composite fabrication methods. The com osite matrix composition was the same as that of the monolithic sausples, so if the space between fibers was filled by the matrix, higher density composites should have resulted. Improved composite fabrication techniques should yield reaction bonded composites with enhanced matrix density.

Fracture surfaces of fabric reinforced samples were examined via SEM. The fracture surface of samples containing the preceramic binder appeared to be much smoother than the rough fracture surface of the composite control samples (Figures 9 and 10). The smooth appearance of the fracture surface of the sample which contained the polysilazane binder implies increased adhesion at the fiber-matrix interface which caused the sample to break in a brittle fashion. 


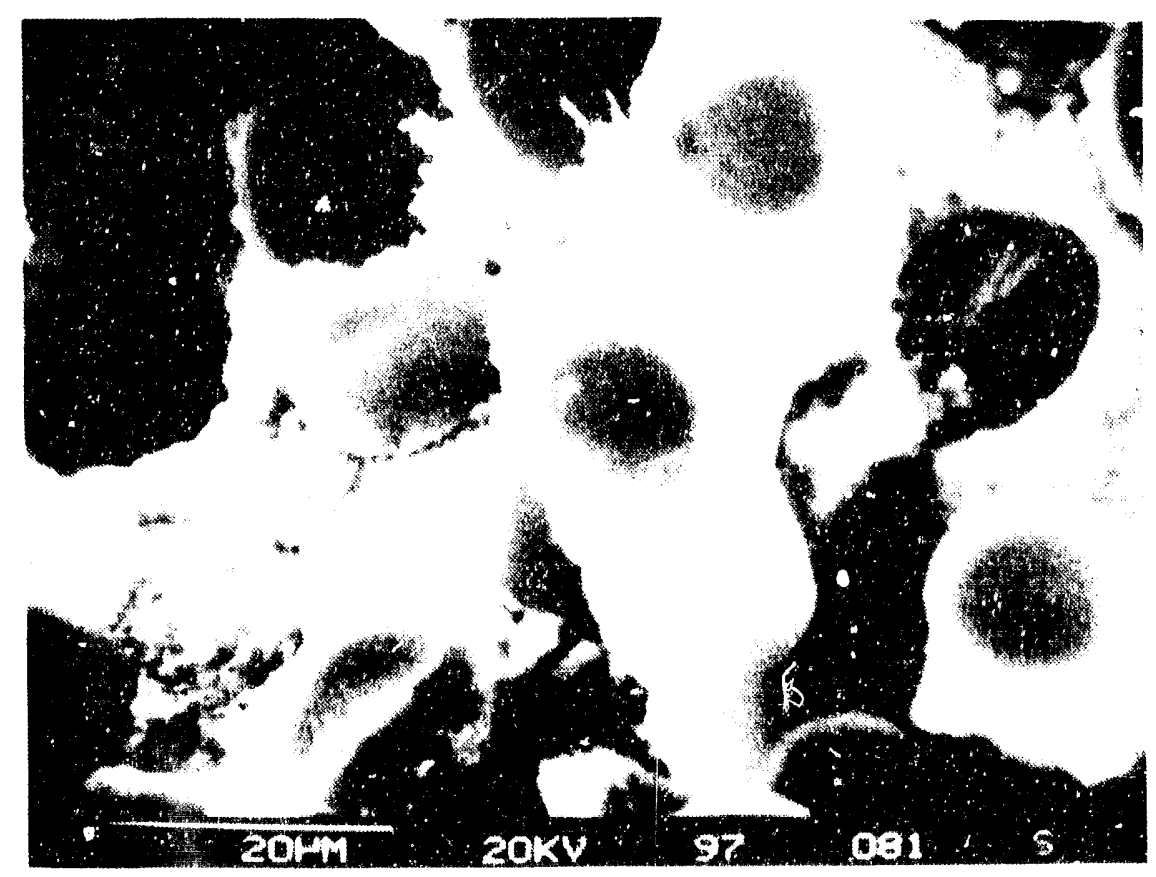

Figure 9. Electron micrograph of fracture surface of fabric reinforced RBSN composite.

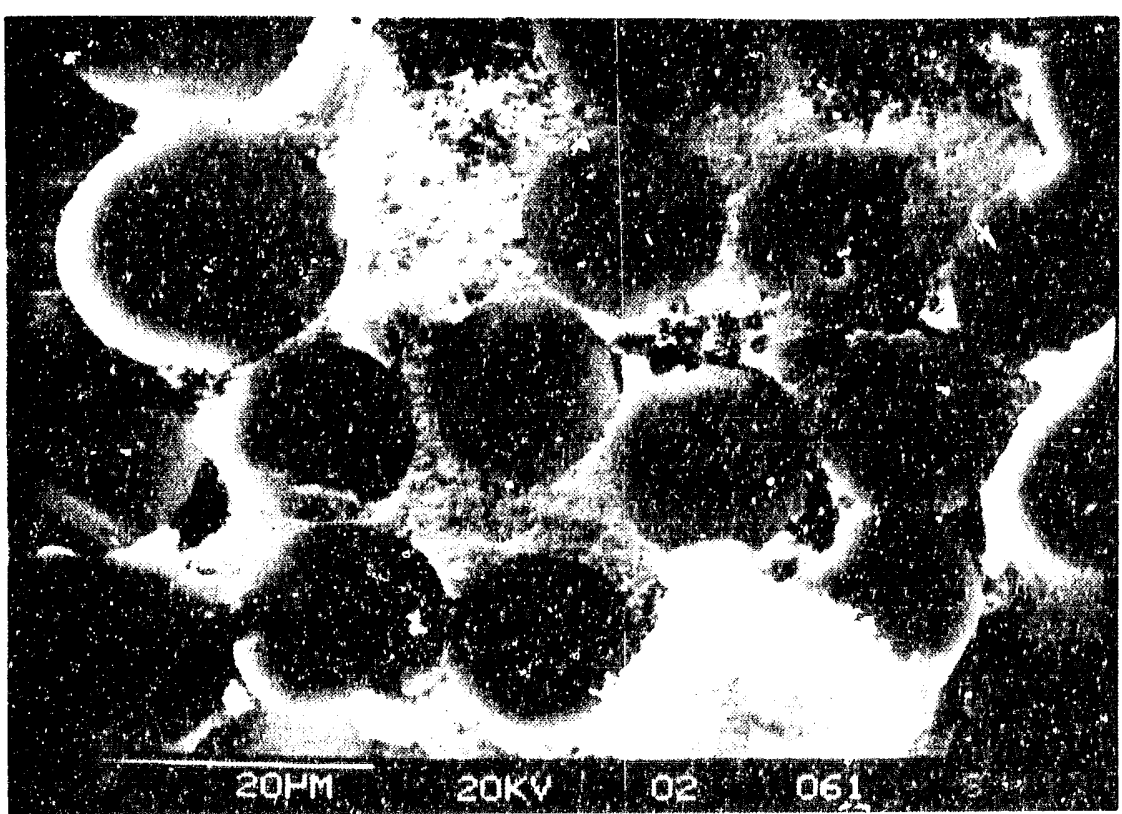

Figure 10. Electron micrograph of fracture surface of fabric reinforced RBSN comprsite with preceramic binder phase. 
A strong bond at the fiber-matrix interface reduces the ability of a crack advancing through the composite to propagate around the fiber reinforcement to cause crack bran hing, fiber pull-out or other energy dissipative mechanisms. Thee mechanisms can enhance the toughness of ceramic composites. Further investigation is required to determine whether this modification of fibermatrix adhesion is due to chemical interactions of the fiber and matrix or other factors.

\section{CONCLUSIONS}

This study has examined the use of two commercially available polyorganosilazanes for application as preceramic binders in a composite composed of silicon carbide fibers in a reaction bonded silicon nitride (RBSN) matrix. Ceramic monolithic and composite samples were produced.

The density of monolithic and whisker reinforced RBSN samples containing the polysilazane binder was increased significantly compared to control samples. Mercury intrusion porosimetry revealed a significant decrease in the pore sizes of samples containing a polyorganosilazane binder compared to control samples. Electron micrographs of samples containing the preceramic binder looked qualitatively similar to those of the control samples containing no precursor. Overall, incorporation of the polysilazane into monolithic and whisker reinforced samples resulted in significantly increased density and decreased porosity.

Nitriding of the RBSN was slightly retarded by the addition of the polysilazane binder. Samples with the preceramic binders contained increased contents of $\alpha$-versus $\beta$-silicon nitride which may be due to interaction of hydrogen evolved from polysilazane pyrolysis with the nitriding process.

Initial efforts to produce continuous fiber reinforced composites via this method have not realized the same improvements in density and porosity which have been observed for monolithic 
and whisker reinforced samples. Further, the addition of preceramic binder resulted in a more brittle fracture morphology as compared to similar composites made without the binder.

Further research is required to relate the chemical and morphological changes resultant from the addition of a preceramic binder to a reaction bonded ceramic system to changes in processibility and performance properties (strength, toughness, creep resistance, etc.) of these materiais.

\section{ACKNOWLEDGEMENTS}

This research was supported by the Department of Energy's Fossil Energy AR\&TD Materials Program, administered through Oak Ridge National Laboratory.

\section{REFERENCES}

1. B. W. Sheldon and J. S. Haggerty, Cer. Eng. Sci. Proc., 9[7-8], $1061-1072$ (1988).

2. T. L. Starr, J. S. Lyons, J. N. Harris, and D. L. Mohr, "Process Development for Reaction Sintered Silicon Nitride Composites", 3rd Annual Conference on Fossil Energy Materials, Oak Ridge, Tennessee (August 1989).

3. J. Jamet, J. R. Spann, R. W. Rice, D. Lewis, Cer. Eng. Sci. Proc., 5 [7-8], 677 (1984).

4. W. J. Lackey, and T. L. Starr, in Fiber Reinforced Ceramic Composites, Materials, Porcessing and Technology, Edited by K. S. Mazdiyasni, Noyes Publications, Park Ridge NJ. p. 397-450 (1990).

5. P. G. Chantrell and P. Popper, "Inorganic Polymers and Ceramics", in P. Popper, Editor, Special Ceramics, Academic Press, New York (1965).

6. R. H. Baney, J. H. Gaul, T. K. Hilty, Mater. Sci. Res., 17, 253 (1984).

7. G. Winter, W. Verbeck, M. Mansmann, U. S. Patent 3892583 (1975).

8. K. J. Wynne and R. W. Rice, Ann. Rev. Mater. Sci., 14, 297 (1984).

9. D. Seyferth, G. H. Wiseman, C. Prud'homme, Mater. Sci. Res., 17, 263 (1984).

10. B. C. Mutsuddy, Ceramics International, 13,4l (1987). 
11. J. Semen. and J. G. Loop, Cer. Eng. Sci. Proc., 11 [9-10], 1987 (1990).

12. K. S. Mazdiyasni, R. West, and L. D. David, J. Am. Ceram. Soc., 61 [11-12], 504, (1978).

13. D. L. Mohr, P. Desai, T. L. Starr, "Production of Silicon Nitride/Silicon Carbide Fibrous Composites Using Polysilazanes as Preceramic Binders", Ceramic Engineering and Science Proceedings, 11 [7-8], 920-930 (1990).

14. D. L. Mohr, P. Desai, T. L. Starr, "Effects of Processing Parameters on Preceramic Binders", Presented at the 15th Annual Conf. on Composites and Advanced Ceramics, Ceramic Engineering and Science Proceedings. (1991).

15. D. L. Mohr, P. Desai, T. L. Starr, "Pretreatment and Pyrolysis of Polysilazanes", Proceedings of the Americun Chemical Societv, Division of Polymer Materials: Science and Engineering, 64, 79-80 (1991).

16. D. L. Mohr, P. Desai, T. L. Starr, "Pretreaiment and Pyrolysis of Polysilazanes", Polymer Preprints, 32[3], 565 (1991).

17. T. L. Starr, J. N. Harris, D. L. Mohr, and J. S. Lyons, "Low Temperature Processing of Reaction Sintered Silicon Nitride", Interim Report, prepared for Oak Ridge National Labs under Sub-contract No 19X-00184C. Contract No. DE-AC05-840R21400 (August 1990).

18. D. L. Mohr, T. L. Starr, J. N. Harris, "Intelligent Control of Advanced Ceramic Processing", Ceramic Engineering and Science Proceedings, 10 [9-10], 414-1424 (1989).

19. A. J. Moulson, "Review: Reaction-bonded Silicon Nitride: Its Formation and Properties", J. Mater. Sci., 15, 1017-1051 (1979).

20. T. L. Starr, D. L. Mohr, J. A. Hanigofsky, and W. J. Lackey, "Development of Silicon Nitride Composites with Continuous Fiber Reinforcements", 6th Annual Conf. on Fossil Energy Materials, Oak Ridge National Laboratory (May 1992). 

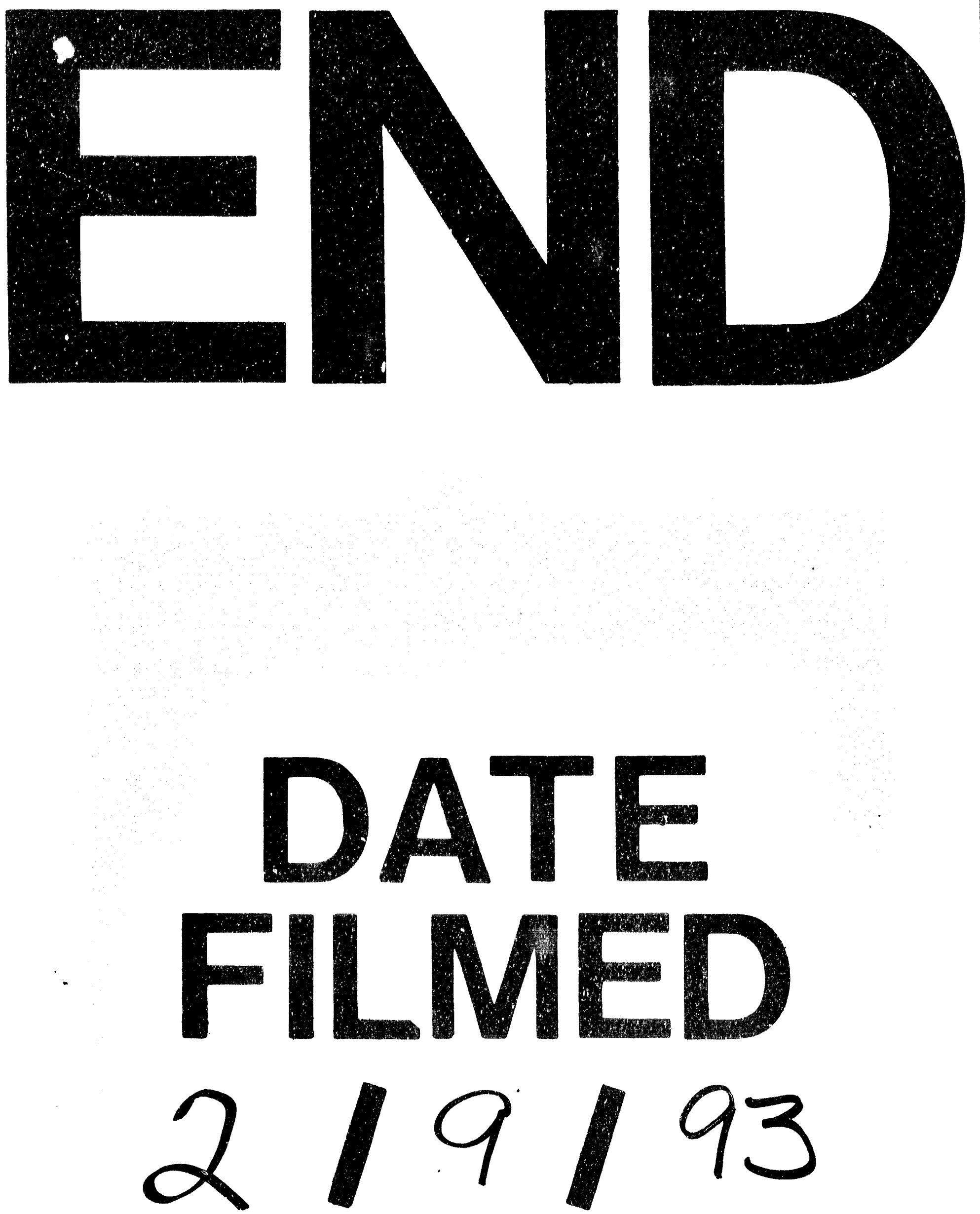
